\title{
THE CHARACTERIZATION ANALYSIS OF ROB HALL IN EVEREST: NEVER LET GO FILM 2015
}

\author{
Risna Budiarti \\ Department of English Education, University of Kuningan, Indonesia \\ Email: risna.budiarti@yahoo.co.id \\ Nani Ronsani Thamrin \\ Department of English Education, University of Kuningan, Indonesia \\ E-mail: nani_cute@yahoo.com
}

APA Citation: Budiarti, R., \& Thamrin, N. R. (2016). The characterization analysis of Rob Hall in Everest: Never Let Go film 2015. Indonesian EFL Journal, 2(1), 71-79

Abstract: This research focuses on Rob Hall's characterizations and moral values found in "Everest: Never Let Go" Film. The aims of this research are to find out Rob Hall's characterizations portrayed in the Film Everest: Never Let Go and the moral values of the Film. The researcher used the theory about psychological analysis (based on Sigmund Freud in Schultz, 2005) to find out Rob characters through his words or sentences in script of Everest; Never Let Go Film and semiotics theory (based on Roland Barthes, 1968, 1990, 1991) to find out the characteristics of Rob Hall through pictures or signs which show his character in Film "Everest: Never Let Go" with print screen of each pictures or signs, and theory of moral value based on George and Uyanga (2014). Qualitative descriptive method was used by the researcher to find out the characteristic of Rob Hall in Everest: Never Let Go Film and the moral values of Rob Hall characterized in the Film. As result, the researcher found 6 characterizations of Rob Hall in Everest: Never Let Go Film, those are Honest, Sociable, Responsible, Assertive, Attentive, and Pessimistic. While, the moral values from this Film was that a leader should be able to support, keep, help, open, responsible, honest, assertive, wise attitude, sacrifice, and direct their team towards better.

Keywords: Characterization Analysis, Rob Hall, Everest: Never Let Go Film, Pyschological Analysis, Semiotics, Moral Value

\section{INTRODUCTION}

Film has an essential that can make the audience interested and feel enjoy. Klarer (1999) states that film is a performing arts that use actors to present the major means of character expression that should be used visual power and needs modes of presentation such as camera angel, editing, slow and fast motion, and is recorded with sound to tell a story in the film. From Klarer's explanation, film is created by literary works of society or even conversely. Film gives the strong impact on the audiences because film has its own characteristics. We can take positive aspects from the film although it also has negative aspects. From film, we also could learn something new such as other cultures, someone's character, how to solve problems or conflicts, or even we have influenced by the film because the film has strong influences for audiences.

Everest: Never Let Go Film is an American-British biographical adventure-disaster survival thriller drama film in 2015 directed by Baltasar Kormakur, written by William Nicholson and Simon Beaufoy, and distributed by Universal Pictures. The actors are Jason Clarke (as Rob Hall), Josh Brolin (as Beck Weathers), John Hawkes (as Dough Hansen), and others. Everest: Never Let 


\section{Risna Budiarti \& Nani Ronsani Thamrin}

The Characterization Analysis of Rob Hall in Everest: Never Let Go Film 2015

Go Film is based on true story experienced by Roberto Hall (Rob Hall) in 1996. This film tells us about a struggle in climbing Everest Mountain in Nepal. Rob Hall is a leader of Adventure Consultants. He became a popular one because he pioneered to make a commercial guiding on Everest for amateur climbers in 1992 . He successfully led 19 clients to summit Everest without anyone died. In 1996, his team got clients to climb Everest once again.

Rob Hall is an interesting character in Everest: Never Let Go Film even though he died in the top of Everest but his character that is strong, friendly, struggle, brave, ambitious, kind, and responsibility to everyone especially to his clients are interesting to be analyzed. Thus, the researcher interested in analyzing his characterization in this film.

In practice, the researcher used the theory about psychological analysis based on Sigmund Freud in Schultz (2005) to find out Rob's characters through his words or sentences in script of Everest: Never Let Go Film and semiotics theory based on Roland Barthes $(1968,1990,1991)$ to find out the characteristics of Rob Hall through pictures which show his character in the Film. The theory about moral values based on George and Uyanga (2014) was also used to find out the moral values of the Film.

Finally, this research intends to achieve the following objectives: finding out Rob Hall's characterizations portrayed in the Film Everest: Never Let Go and the moral values of the Film Everest: Never Let Go.

\section{METHOD}

In conducting the research, qualitative descriptive method is used by the researcher to find out the characteristic of Rob Hall in Everest:
Never Let Go Film and the moral values of Rob Hall characterized in the film. According to Creswell (2012, p. 16), "qualitative research is the research exploring a problem and developing a detailed understanding of a central phenomenon." In other words, Creswell (2012) explains that the description in qualitative research includes some information about person, place, and setting in the object of our research as details of each information. Qualitative descriptive was considered as an appropriate method for this research because this method helps the researcher to solve the problems found in this research. The researcher used theory about psychological analysis to find out Rob characters through his words or sentences in script of Everest: Never Let Go Film and semiotics to find out the characteristics of Rob Hall through pictures which show his character in the Film.

In this study, the data was taken from the dialogues on the script of each scene from beginning to the end of the story in the Film Everest: Never Let Go. While, pictures and signs were used to support characterization of Rob Hall in the Film.

In collecting the data, the researcher did some steps as follows: First, choosing and downloading the film. Second, watching and reading the subtitles of Everest: Never Let Go film to more understand about the film. Third, collecting or selecting utterances, words, or even sentences that show the character of Rob Hall, scene by scene from the script. Fourth, the researcher analyzes and identifies Rob Hall character in the Film Everest: Never Let Go through psychological analysis and semiotics. In psychological method, the researcher used id, ego, and superego based on Freud in Schultz (2005) theory by focusing on Rob Hall' utterances in the Film. While in semiotics, the 
researcher used denotation, connotation, and myth as signs of Rob Hall character based on Barthes' (1968, 1990, 1991) theory in the Film Everest: Never Let Go by capturing screen which show Rob Hall's characterization. Fifth, describing or interpreting the data accord with those theories. Sixth, finding out or searching the dominant type characterization of Rob Hall in the Film. Last, concluding the characteristic of Rob Hall and finding out the moral value of the film Everest: Never Let Go.

Then, in analyzing the data, the researcher used psychological analysis theory based on Sigmund Freud to find out the characterization of Rob Hall through the dialogue on the script. Here, the researcher analyzes each sentence said by Rob Hall in the film which shows Rob Hall's character by using a note to write the sentences, duration, and the condition when Rob Hall expresses his words. In addition, the researcher used semiotics theory based on Roland Barthes to find out the characterization of Rob Hall through the pictures or signs on the Film. The researcher captured the screen on the computer in every sign that shows Rob Hall's character. Then, the researcher interpreted it based on Barthes theory. After Rob Hall's character has been drawn, the researcher analyzed the moral value of this film based on George and Uyanga theory. The final step was the researcher interpreted the data that has been arranged and analyzed.

\section{RESULTS AND DISCUSSION}

After analyzing the data, the researcher found 6 characterizations of Rob Hall in Everest: Never Let Go Film. Those are Honest, Sociable, Responsible, Assertive, Attentive, and Pessimistic. Those characterizations are described below.

Figure 1. Characterizations of Rob Hall in Everest: Never Let Go Film

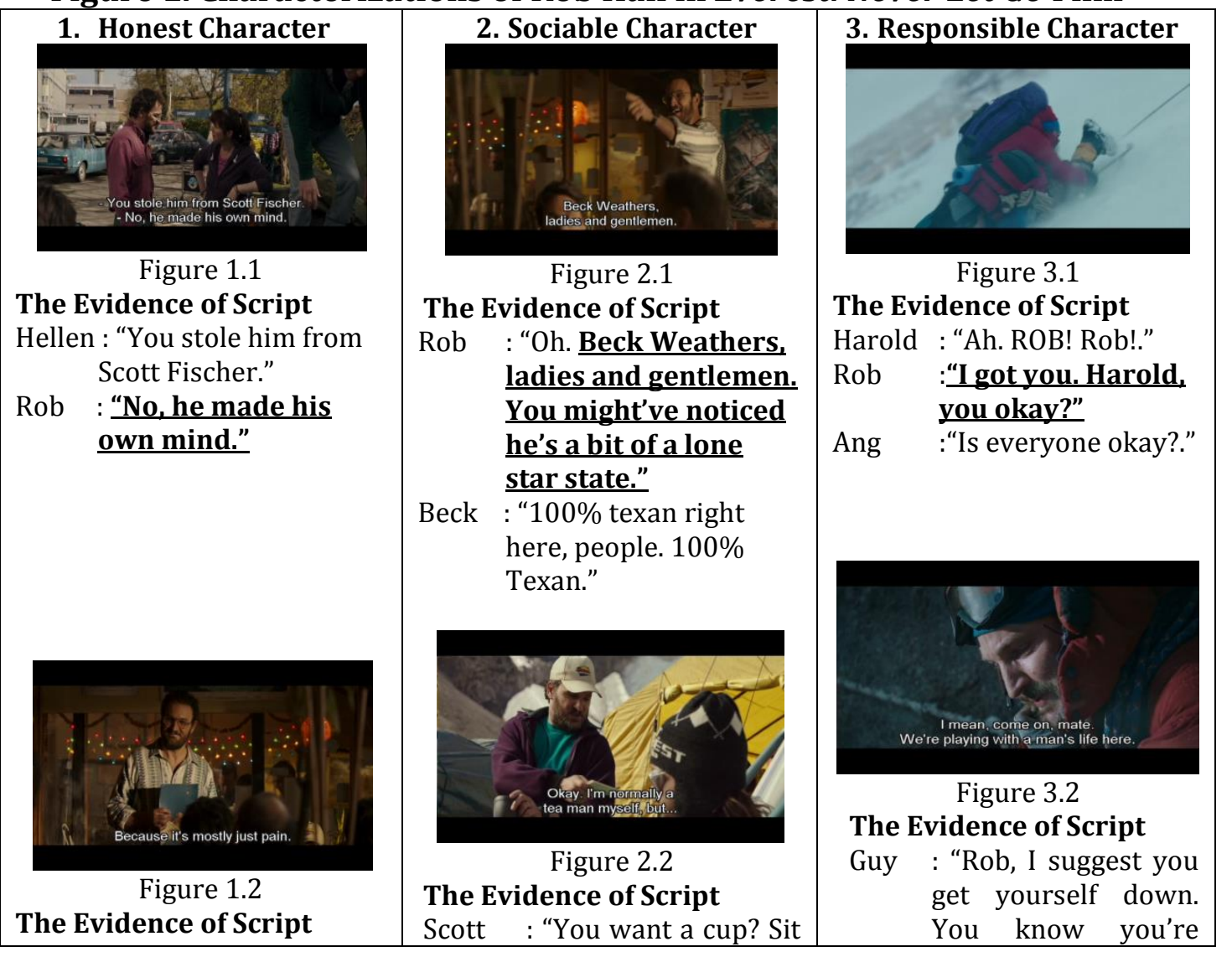




\section{Risna Budiarti \& Nani Ronsani Thamrin}

The Characterization Analysis of Rob Hall in Everest: Never Let Go Film 2015

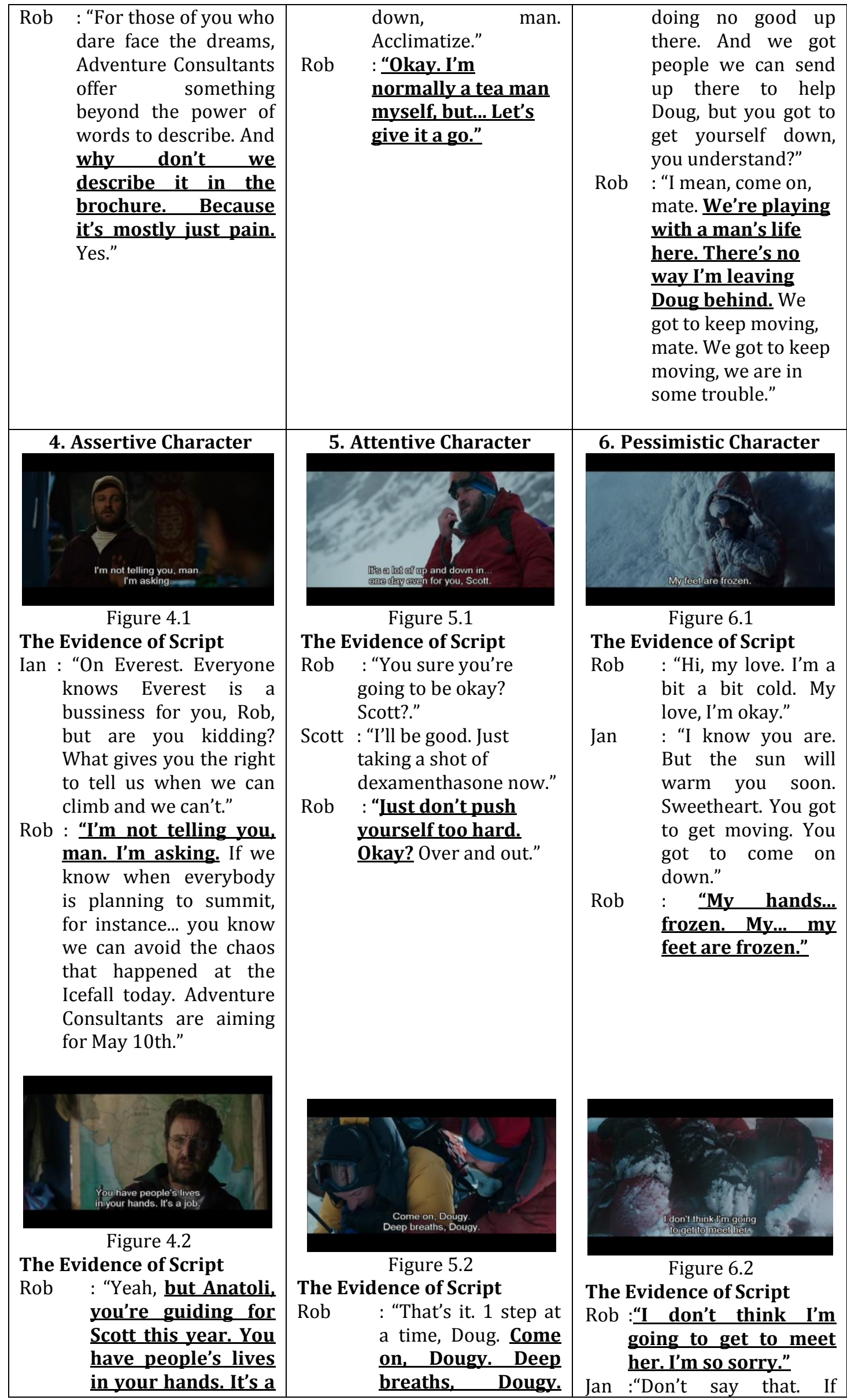




\begin{tabular}{|c|c|c|c|}
\hline Anatoli : "Never & & $\begin{array}{l}\text { Come on, mate. } \\
\text { Keep it on. Keep it }\end{array}$ & $\begin{array}{l}\text { anyone can make it, you } \\
\text { can. Remember." }\end{array}$ \\
\hline $\begin{array}{l}\text { Never will. Bigger } \\
\text { problems if you run } \\
\text { out." }\end{array}$ & Doug & : "Rob." & $\begin{array}{c}\text { Rob :"I love you. Please } \\
\text { don't worry too much. } \\
\text { Good bye, my love." }\end{array}$ \\
\hline
\end{tabular}

\section{Honest Character}

Figure 1.1 showed Rob's honesty to Helen by using the sharp eyes and showed Rob's seriousness to tell the truth by maintaining his body towards Helen. Although Helen refused Rob's news firmly with raising her arms to her waist, Rob was still on his stand. It can be seen that Rob is a honest character who would stare intently to his opponent talking. It can be seen on the bold and underlines words of Rob Hall in the scene time 00:03:32 until 00:03:54 when Rob and his teams are in the parking area of the Airport. Rob told to Helen and Guy that their teams got Jon Krakauer. Jon Krakauer was a journalist from Outside Magazine. Previously, Jon Krakauer was a journalist from Scott Fischer's teams, Mountain Madness. Rob was showing his superego because he had already known what he would get after he got Jon Krakauer. Rob's character was seen when he tried to explain the reason why Krakauer joint his teams. Rob tried to explain it calmly. Even though Helen supposed him that Rob got an expensive payment from Krakauer but Rob refuted her calmly because he had already known its advantages and disadvantages for the teams. From Figure 1.1, the researcher saw that Rob was a honest character since Rob explained the truly condition and he did not think that he stole Krakauer from Scott Fischer but Outside Magazine was calling to Rob first.

On Figure 1.2, Rob showed his honesty that belonged to intellectual component by telling the truth to his clients. With a little smile, Rob told the truth to his clients closely. Rob held a guidebook, it can be seen that Rob told the truth based on the guidebook and the reality on the trek. It can be seen in the scene 00:07:38 until 00:07:59. Rob told to his clients about his team, Adventure Consultants. He told the right and wrong of Adventure Consultants. Rob shows his ego. Rob knew that his clients had to know the Adventure Consultants deeply. Rob told the reason why Adventure Consultant did not describe the truly condition and could not say with words because he knew that it was mostly just pain. Then, Rob asked Mike to show his toe because Mike lost his toe when climbing Everest. Rob showed Mike's toe to make his clients believe and more be careful when trekking Everest. From the figure 1.2 above, the researcher saw that Rob was honest character by telling the good or bad of Everest's condition and also Adventure Consultants. He could not think that he should have any clients but he just thought how to make them believe.

\section{Sociable Character}

From Figure 2.1, Rob was welcoming and introducing Beck Weathers closely with a little smile and laugh. By pointing forward to Beck, Rob introduced Beck to others' clients. Rob also came to Beck's seat. It happened in the scene time 00:08:27 until 00:08:42. Rob was looked like very kindly and friendly on his face. Rob shows his superego. It could be seen when Rob came close to Beck with a little laughing and smiling. The meaning from this picture was that to become a leader, someone should be got closeness with all teams to get each others' sympathy and knew how to make them felt comfort. Rob was acted purely and looked so close with his clients. Rob wanted to show his closeness in front of all clients in order to 


\section{Risna Budiarti \& Nani Ronsani Thamrin}

The Characterization Analysis of Rob Hall in Everest: Never Let Go Film 2015

make his clients could get the closeness each others.

Rob showed sociable character on

Figure 2.1 in the scene time 00:17:01 until 00:17:21. Rob was using the brown hat and purple jacket. Rob held a paper on the right hand and a cup of coffee on the left hand as if showed that Rob was a sociable character because Rob was holding a cup of coffee from Scott and wanted to lay away a paper even though he did not like coffee. It happened when Rob walked around Base Camp and Scott Fischer accosted him. They showed their friendly each other. Rob showed his superego when he was offered a cup of coffee from Scott Fischer. Actually, he did not like coffee but he tried to appreciate what Scott given. The researcher saw that Rob was sociable character because he could diffuse with others teams such Scott Fischer who was the leader of Mountain Madness teams. He always appreciated what others gave to him although he did not like it.

\section{Responsible Character}

On Figure 3.1 above, Rob was wearing red jacket and blue bag. Rob's look was arrested Harold who was going to fall. Rob catched Harold abruptly by catching Harold's feets. Rob as responsible character also can be seen as on the bold and underlines words in the scene time 00:43:30 until 00:44:34. Rob shows his id when he helped Harold who fell down because the icefall came to his teams and it happened in unconscious condition. It can be seen in the first conversation when Harold was screaming and Rob immediately catched him. The researcher saw that Rob has a responsible character because he could help his clients abruptly in unpredictable condition. He also showed that he had always ready to help everyone who needed the help.

On the Figure 3.2, Rob was talking to Guy through his hand-talk. Even though the picture just showed Rob' face but it can be seen that Rob was a responsible character. Rob bowed his head and spoke firmly to show that he was playing with a man's life so he could not leave Doug alone on the top. Rob's responsible character is shown on the bold and underlines words in the scene time 01:13:37 until 01:13:56. Rob showed his ego when Guy asked Rob to leave Doug and bring himself down. Rob would not to leave Doug alone. However, it was danger for Doug and himself. Rob tried to make Guy believed that Rob was helping a man's life and there was no way to leave Doug. From this, the researcher saw that Rob was a responsible character. Rob was responsible thoroughly in all clients' life. Rob did not leave his clients alone in the trouble.

\section{Assertive Character}

On Figure 4.1, Rob maintained his head and spoke firmly. Rob brandished his right hand to assert to Ian. Rob did not make misunderstanding with his friends. It can be seen in the scene time 00:30:12 until 00:30:49. Rob showed his superego. It happened in the meeting with all teams talking about the schedule. Ian as leader of other teams said that Everest just became Rob' business and he thought that Rob did not reserve to ban when should climb or not climb on Everest. Suddenly, Rob showed his assertive with saying "I'm not telling you, man. I'm asking." So, from that statement, the researcher saw him as assertive character by seeing from what he said. Rob did not only think about himself and his teams, but also all teams who climb Everest.

On Figure 4.2, Rob puckered his forehead. Rob showed his amaze but still spoke firmly to assert Anatoli that he should use oxygen. Rob was staring at Anatoli earnestly. It can be seen in the scene time 00:33:46 until 00:34:16. Rob 
showed his superego when Anatoli said that he would not use oxygen when climbing to the Summit of Everest. Anatoli thought that if he used oxygen, it would make a bigger problem when he ran out of the Summit of Everest. Rob convinced Anatoli that Anatoli should guide Scott Fischer in that years, 1996, and Anatoli had all people's lives in his hands because he should responsible to Mountain Madness teams. Unfortunately, Anatoli did not want to hear what Rob and Scott said. Rob gave understanding to use oxygen on trekking Everest because it was an important thing. From figure 4.2, the researcher saw that Rob was a wise character from his explanation to all clients to use oxygen because he knew that all clients' destiny is in his hands.

\section{Attentive Character}

On Figure 5.1, it can be seen that Rob was looking down and holding his hand-talk. Rob was talking with Scott. With his anxious face, Rob told to Scott that Scott should take a rest. It can be seen in the scene 00:44:35 until 00:45:24. Rob showed his superego because he knew Scott Fischer's condition. Rob gave his attention to Scott to rest about one day in Base Camp. Rob said "don't push yourself too hard" to Scott because he did not want to let his friend ill. From the Figure, the researcher saw that Rob was an attentive character that he could not let everyone ill because they pushed them too hard. By looking down and using hand-holder, Rob's sound was quiet and tried to convince Scott to climb tomorrow because of up and down in the way to Camp 1.

On the Figure 5.2, Rob showed his attentive when helping Doug. Rob held Doug's body that fell and weak. With glared at Doug, Rob tried to open Doug's mask. It can be seen in the scene time 00:55:53 until 00:56:29. Rob showed his ego. Rob gave a spirit to Doug to never give up. Rob showed his attention to Doug when climbing down to the bottom because of Doug lost his oxygen. Rob guided Doug to keep his way and made Doug's believe that he could do it. Rob did not want to leave Doug alone although he knew the black blizzard would come up to the Summit of Everest. From Figure 5.2 above, the researcher saw that Rob was an attentive character because he did not let everyone struggle alone.

\section{Pessimistic Character}

On the Figure 6.1, Rob's body and his eyeglasses were covered by snow. By holding the hand-talk, Rob tried to talk with Jan and tell his condition. Rob showed a pessimistic character as on the bold and underlines words. It can be seen in the scene time 01:30:52 until 01:31:53. Rob showed his superego. Rob's teams, Adventure Consultants, tried to call Jan to give him a spirit to move on to the bottom. The conversation showed that Jan was very worry about Rob's condition. Unfortunately, Rob had a bit cold. Rob told Jan that he could not move anymore because his hands and feet were frozen. Jan tried to convince Rob that the sun would come and warm his body. Jan said that she would send people up and bring a tea and oxygen but Rob should get moving. From Figure 6.1 above, the researcher saw that Rob was a pessimistic character because although he got a spirit from Jan, but he still could not move.

From Figure 6.2, Rob laid on the snow but still kept his hand-talk. Rob closed his eyes and folded his hand on his stomach. It can be told that Rob was trembled and he could not continue his trekking. His face showed that he was weak. It can be seen in the scene time 01:38:18 until 01:40:35 that included Rob's ego. Guy tried to call Jan and ask her to talk with Rob with the hope that 


\section{Risna Budiarti \& Nani Ronsani Thamrin}

The Characterization Analysis of Rob Hall in Everest: Never Let Go Film 2015

Rob would get more spirit to keep going down to the bottom. In the first conversation between Rob and Jan, Rob asked about her condition. But Jan truly worried about Rob and wanted Rob to say "I'm good" but unfortunately Rob had a little frostbite. Jan asked Rob to keep moving continuously but Rob could not. Rob asked Jan about his daughter, Sarah. Rob thought that he may could not meet his daughter because he lost his balance and hoped he can keep moving to the bottom. Rob asked Jan to treat and love Sarah although he could not beside her. Rob became a pessimistic because his body was covered by ice and frozen and no one came to help him. Rob showed his ego when he told that he might never meet his baby. By closing his eyes, it indicated that he had not strong to go or move anymore, and Rob wanted Jan not to worry too much about him and finally Rob said goodbye to Jan. At the time, Rob passed away on the South Summit on Hillary Step of Everest.

In addition to 6 characterizations of Rob Hall in Everest: Never Let Go Film mentioned above, the researcher also found the moral values of this film. In finding the moral value, the researcher used the moral values theory proposed by George and Uyanga (2014), as follow:

1. A leader should be able to support and direct their team towards better.

2. A leader should be able to keep and help their team.

3. A leader should become their team as their family.

4. A leader should be able to open everything good or bad to their team.

5. A leader should responsible and honest to their team in every situation and condition.

6. A leader should be able to show his assertive when their team got the wrong ways.
7. A leader should have a wise attitude in every decision in order to avoid any troubles in their team.

8. A leader should be willing to sacrifice in order to save their team.

9. A leader should not to distinguish their team.

By using the theory, the researcher finally got moral values of the Everest: Never Let Go Film that a leader should be able to support, keep, help, open, responsible, honest, assertive, wise attitude, sacrifice, and direct their team towards better.

\section{CONCLUSION}

Everest: Never Let Go Film is an American-British biographical adventure-disaster survival thriller drama film 2015 directed by Baltasar Kormakur, written by William Nicholson and Simon Beaufoy, and distributed by Universal Pictures. The Film was released on September 18, 2015. The duration of this Film is 02:01:04. The genres of this Film are adventure, biography, drama, history, and thriller. This Film is based on true story experienced by Roberto Hall (Rob Hall) in 1996. In 1992, Rob successfully led 19 clients to summit Everest without anyone died. In 1996, his team got clients to climb Everest again. It was different from his climbing before, Rob got any obstacles when he would turn down into a bottom until he passed away in the South Summit on Hillary Step.

Here, the researcher found 6 characterizations of Rob Hall in Everest: Never Let Go Film. The 6 characterizations are honest, sociable, responsible, assertive, attentive, and pessimistic. The researcher gets Rob's characterization after reading whole script and watching the Film. The researcher used the theories of Psychological Analysis based on Sigmund Freud in Schultz (2005) and Semiotics 
based on Roland Barthes (1968, 1990, 1991). Then, the researcher also gets moral values from this Film that a leader should be able to support, keep, help, open, responsible, honest, assertive, wise attitude, sacrifice, and direct their team towards better.

\section{REFERENCES}

Barthes, R. (1968). Elements of semiology: New York, NY: Hill and Wang. . (1990). S/Z. United Kingdom, UK: Blackwell Publishing Ltd. . (1991). Mythologies. New York, UK: The Noonday Pr.

Creswell, J. W. (2012). Educational research: Planning, conducting and evaluating quantitative and qualitative research (4th Edition). United States, US: Pearson Education.
Everest: Synopsis. Retrieved March 31st, 2016 from http://m.imdb.com/title/tt2719848/s ynopsis?ref_=m_tt_stry_pl

George, I. N. \& Uyanga, U. D. (2014). Youth and moral values in changing society. IQSR Journal of Humanities and Sosial Science (IQSR_JHSS), 19(6), 40-44.

Klarer, M. (1999). An introduction to literary studies. London, England: Routledge.

Kumar, R. (1997). Research methodology: A step-by-step guide for beginner (2nd Edition). New Delhi, India: Sage Publication.

Schultz, D. P \& Schultz, S. E. (2005). Theories of personality (8th ed.). USA: Thomson Wadsworth.

Standford Encyclopedia of Philosophy: Kant's moral philosophy. (2008). Retrieved February 2nd, 2016 from http://plato.stanford.edu/entries/kant -moral/ 